Article

\title{
Effect of Level and Downhill Running on Breathing Efficiency
}

\author{
Matthew D. Cook, Stephen D. Myers, John S. M. Kelly and Mark E. T. Willems * \\ Department of Sport \& Exercise Sciences, University of Chichester, West Sussex PO19 6PE, UK; \\ E-Mails: m.cook@chi.ac.uk (M.D.C.); s.myers@chi.ac.uk (S.D.M.); j.kelly@chi.ac.uk (J.S.M.K.) \\ * Author to whom correspondence should be addressed; E-Mail: m.willems@chi.ac.uk; \\ Tel.: +44-1243-816-468; Fax: +44-1243-816-080.
}

Academic Editor: Arno Schmidt-Trucksäss

Received: 23 April 2014 / Accepted: 14 January 2015 / Published: 23 January 2015

\begin{abstract}
Ventilatory equivalents for oxygen and carbon dioxide are physiological measures of breathing efficiency, and are known to be affected by the intensity and mode of exercise. We examined the effect of level running (gradient $0 \%$ ) and muscle-damaging downhill running $(-12 \%)$, matched for oxygen uptake, on the ventilatory equivalents for oxygen $\left(\dot{\mathrm{V} E} / \dot{\mathrm{V}} \mathrm{O}_{2}\right)$ and carbon dioxide $\left(\dot{\mathrm{V} E} / \mathrm{VCO}_{2}\right)$. Nine men $(27 \pm 9$ years, $179 \pm 7 \mathrm{~cm}, 75 \pm 12 \mathrm{~kg}$, $\left.\dot{\mathrm{VO}_{2 \max }}: 52.0 \pm 7.7 \mathrm{~mL} \cdot \mathrm{kg}^{-1} \cdot \mathrm{min}^{-1}\right)$ completed two 40 -min running bouts $(5 \times 8$-min with 2-min inter-bout rest), one level and one downhill. Running intensity was matched at $60 \%$ of maximal metabolic equivalent. Maximal isometric force of m.quadriceps femoris was measured before and after the running bouts. Data was analyzed with 2-way ANOVA or paired samples $t$-tests. Running speed (downhill: $13.5 \pm 3.2$, level: $9.6 \pm 2.2 \mathrm{~km} \cdot \mathrm{h}^{-1}$ ) and isometric force deficits (downhill: $17.2 \pm 7.6 \%$, level: $2.0 \pm 6.9 \%$ ) were higher for downhill running. Running bouts for level and downhill gradients had $\mathrm{V}_{2}$, heart rates and respiratory exchange ratio values that were not different indicating matched intensity and metabolic demands. During downhill running, the $\dot{\mathrm{VE}} / \mathrm{V}_{2}$, (downhill: $29.7 \pm 3.3$, level: $27.2 \pm 1.6$ ) and $\dot{\mathrm{VE}} / \dot{\mathrm{V}} \mathrm{CO}_{2}$ (downhill: $33.3 \pm 2.7$, level: $\left.30.4 \pm 1.9\right)$ were $7.1 \%$ and $8.3 \%$ higher $(p<0.05)$ than level running. In conclusion, breathing efficiency appears lower during downhill running (i.e., muscle-damaging exercise) compared to level running at a similar moderate intensity.
\end{abstract}

Keywords: eccentric exercise; muscle damage; ventilatory equivalent; metabolic equivalent; moderate intensity; treadmill running 


\section{Introduction}

During dynamic whole-body exercise, the main function of the respiratory system is to supply oxygen $\left(\mathrm{O}_{2}\right)$ to the blood and eliminate the carbon dioxide $\left(\mathrm{CO}_{2}\right)$ produced in the working skeletal muscles. Over a broad range of exercise intensities, a change in exercise intensity is associated with a change in breathing responses, e.g., a change in minute ventilation, i.e., the volume of exhaled air per minute, allowing increased oxygen consumption and carbon dioxide elimination. Measures of breathing efficiency are the ventilatory equivalents for oxygen $\left(\mathrm{O}_{2}\right)$ and carbon dioxide $\left(\mathrm{CO}_{2}\right)$ which are the ratios of minute ventilation to $\mathrm{O}_{2}$ consumption $\left(\dot{\mathrm{VE}} / \dot{\mathrm{VO}}_{2}\right)$, and minute ventilation to $\mathrm{CO}_{2}$ output $\left(\dot{\mathrm{VE}} / \dot{\mathrm{VCO}}_{2}\right)$, respectively [1].

Breathing efficiency and exercise intensity are related [2]. Breathing efficiency decreases from low-intensity exercise reaching a plateau value at moderate to high intensities [2]. Breathing efficiency is also related to the exercise modality. For example, higher $\dot{\mathrm{V} E} / \mathrm{V}_{2}$ were reported for arm exercise compared to leg exercise [3]. Additionally, running had a higher $\dot{\mathrm{V} E} / \mathrm{V}_{2}$ ratio than simulated swimming [4], the $\dot{\mathrm{V} E} / \dot{\mathrm{V}} \mathrm{CO}_{2}$ during treadmill running was higher than cycle ergometry at submaximal intensity [5], but higher for cycle ergometry than uphill treadmill running at maximum intensity [6].

Running is a common exercise modality, with the gradient determining whether the exercise consists mainly of concentric or eccentric contractions. Running exercise at a negative gradient (i.e., downhill running) is an activity that requires primarily eccentric contractions of skeletal muscles (i.e., lengthening muscle actions). When running at similar speeds, the eccentric contractions of skeletal muscles will require a lower oxygen demand than level running with concentric contractions [7]. In addition, the physiological responses by the cardiovascular and respiratory systems during eccentric exercise are lower compared to concentric exercise. This lower response may be partly due to recruitment of motor units being less for eccentric compared to concentric contractions at any given force [8]. Eccentric contractions are also known to have higher force production, and the combination of high force and low fibre recruitment makes contractile proteins more susceptible to muscle damage because of increased mechanical stress applied per cross-bridge. When individuals are not accustomed to the eccentric exercise, muscle damage occurs. Muscle damage is observed by acute force loss during maximal voluntary contractions (MVC), and measurement of maximal voluntary force is considered the best method to establish muscle damage [9].

Because the exercise modality is related to breathing efficiency and downhill running known to be muscle-damaging exercise, it is possible that the ventilatory equivalents during level running and downhill running are different. Previous studies, using countermovement jumps [10] or squat exercise [11] to induce muscle damage, demonstrated increased ventilatory equivalents for $\mathrm{O}_{2} 48 \mathrm{~h}$ later. These observations clearly demonstrate that the presence of muscle damage influences breathing efficiency. The exact mechanisms for the decrease in breathing efficiency are unknown, yet are postulated to relate to the process of muscle damage. It is not known whether there is an acute effect of muscle-damaging exercise with primarily eccentric contractions on breathing efficiency.

Therefore, the aim of the present study was to examine the effects of muscle-damaging downhill treadmill running and non-damaging level treadmill running, matched for intensity on the ventilatory equivalents for $\mathrm{O}_{2}$ and $\mathrm{CO}_{2}$. It was hypothesized that the ventilator equivalents for $\mathrm{O}_{2}$ and $\mathrm{CO}_{2}$ would be higher for downhill treadmill running compared to level running at similar intensity. 


\section{Subjects and Methods}

\subsection{Participants}

Nine healthy men (age $27 \pm 9$ years, height $179 \pm 7 \mathrm{~cm}$, body mass $75.3 \pm 12.0 \mathrm{~kg}$, $\dot{\mathrm{V}} \mathrm{O}_{2 \max } 52.0 \pm 7.7 \mathrm{~mL} \cdot \mathrm{kg}^{-1} \cdot \mathrm{min}^{-1}$ ) volunteered for the study and provided written informed consent. Participants were physically active, had within the last two months no activities with unaccustomed eccentric contractions of knee extensor muscles, and were free from musculoskeletal injury. The study was approved by the University of Chichester Research Ethics Committee with all procedures performed in accordance with the 1964 World Medical Association Declaration of Helsinki.

\subsection{Study Design}

Participants attended the laboratory for five visits, all completed at a similar time of the morning ( $<2 \mathrm{~h}$ difference). In brief, in the first visit, participants were familiarized for the performance of an isometric voluntary maximal contraction (iMVC) of the m.quadriceps femoris of both legs. In the same session, participants also completed an incremental submaximal treadmill ( $0 \%$ gradient) test for determination of level running speed and metabolic equivalent (MET) and a maximal oxygen uptake test $\left(\dot{\mathrm{V}}_{2 \mathrm{max}}\right)$. In the second visit, participants arrived at the laboratory following a $12 \mathrm{~h}$ fast and sat resting for $10 \mathrm{~min}$ before a 10-min collection of expired gas for determination of the oxygen cost during quiet sitting (i.e., resting metabolic equivalent, 1-MET, $3.1 \pm 0.8 \mathrm{~mL} \cdot \mathrm{kg}^{-1} \cdot \mathrm{min}^{-1}$, resting heart rate $57 \pm 8$ beats $\left.\cdot \min ^{-1}\right)$. In the third visit, participants completed an incremental submaximal treadmill tests ( $-12 \%$ gradient) for determination of the relationship between downhill running speed and MET. In the fourth and fifth visit, performed at least 2 weeks later with at least 1 week between the 4 th and 5th visit, participants performed $40 \mathrm{~min}$ level (0\% gradient) and downhill ( $-12 \%$ gradient) running at $60 \%$ maximal MET, respectively. The same treadmill was used for all testing.

\subsection{Maximal Voluntary Contraction}

Force with isometric maximal voluntary contractions of the m.quadriceps femoris was assessed on a custom built chair (University of Chichester, Chichester, UK) with $90^{\circ}$ hip and knee flexion. Participants were instructed to maintain upper body position during contractions of the m.quadriceps femoris which was facilitated with Velcro straps secured around the chest and waist. A cuff was positioned around the ankle of the participants (proximal to the fibular notch and medial malleolus) and attached via a steel chain to a s-beam load cell (RS $250 \mathrm{~kg}$, Tedea-Huntleigh, Cardiff, UK). Participants received standard instructions in preparation of a maximal voluntary isometric contraction including strong verbal encouragement during the task [12]. Force was recorded on a computer with a sampling frequency of $1000 \mathrm{~Hz}$ using Chart 4 V4.1.2 (ADInstruments, Oxford, UK) and displayed at $1.5 \mathrm{~m}$ in front of the participants. Prior to performing the iMVC, participants performed three 5-second sub-maximal contractions $(\sim 200 \mathrm{~N})$ to become accustomed to the experimental set up. Participants performed three voluntary maximal isometric contractions with the maximal isometric force quantified as the highest mean over a time period of $0.5 \mathrm{~s}$. The highest force values were taken for analysis. Participants rested for 2 min between each maximal contraction. The measurement of iMVC was practiced in Visit 1 and 
performed immediately before and following the running bouts in Visits 4 and 5. Coefficient of variation of repeated maximal isometric force measurements was $4.6 \%$.

\subsection{Maximal Oxygen Consumption}

Maximal oxygen uptake was established using an incremental exercise test on a motorized treadmill (HP Cosmos Pulsar, Bodycare Direct, Southam, UK). Expired gas samples were collected using Douglas Bags (Cranlea Human Performance Ltd., Birmingham, UK). Starting speed was $9 \mathrm{~km} \cdot \mathrm{h}^{-1}$ with a gradient of $1 \%$ [13]; the gradient was increased by $1 \% \cdot \mathrm{min}^{-1}$ during for the first five min after which speed was increased by $0.1 \mathrm{~km} \cdot \mathrm{h}^{-1}$ every five seconds until the participant reached volitional exhaustion. Expired gas was collected in separate bags for the last 3-min of the test. The last collection bag was only analyzed when collection time and expired volume was greater than $30 \mathrm{~s}$ and $65 \mathrm{~L}$, respectively. Expired and inspired fractions of oxygen and carbon dioxide were measured using a gas analyzer (Series 1400 gas analyzer, Servomex, Crowborough, UK), calibrated using three- and two-point calibration for oxygen and carbon dioxide, respectively (Linde Gas UK Ltd., West Bromwich, UK) and volumes measured with a calibrated Harvard dry gas meter (Harvard Apparatus Ltd., Edenbridge, UK). Volumes were standardized to STPD conditions and Haldane transformation used for calculation of gas volumes. Participants $\dot{\mathrm{V}} \mathrm{O}_{2 \max }$ was converted in MET (i.e., maximal MET, $16.7 \pm 5.8$ ) to allow intensity matching of running for experimental Visits 4 and 5.

\subsection{Level and Downhill Running}

The level ( $0 \%$ gradient) and downhill ( $-12 \%$ gradient) running bouts in Visits 4 and 5 were performed following an overnight fast. For all participants, in Visits 1 and 3, the MET value for level and downhill running at speeds of $8,9,10$ and $11 \mathrm{~km} \cdot \mathrm{h}^{-1}$ (each speed for $5 \mathrm{~min}$ ) were measured. Subsequently, the relationship between running speed and MET was calculated with linear regression to allow matched-intensity exercise for level and downhill running. Exercise intensity for the $40 \mathrm{~min}$ level and downhill running (i.e., 5 stages of 8-min with 2-min rest between stages) was set at $60 \%$ maximal MET with heart rate recording. In the last minute of each 8 -min stage, expired gas was collected using the Douglas Bag technique and similar techniques for analysis and calculations were used as for the expired air samples collected during the maximum oxygen uptake test. The heart rate at end of each expired air collection was recorded (FS1, Polar, Kempele, Finland).

\subsection{Statistical Analysis}

All statistical analyses were completed using SPSS 20.0 (SPSS, Chicago, IL, USA). Sample size was based on mean $\pm \mathrm{SD}$ for ventilatory equivalent for oxygen at $60 \% P_{\max }[10]$ (alpha error level is 0.05 and statistical power is 0.8 ) to detect a $4 \%$ difference in the downhill running group. Data normality assumptions were assessed using Kolmogorov-Smirnov test. A two-way ANOVA (time and condition) was used to examine the difference in force of the iMVC, with differences located with pre-planned Bonferroni corrected paired samples $t$-tests. For the five expired air collections during each level and downhill running bout, oxygen consumption, respiratory exchange ratio, and ventilatory equivalents for oxygen and carbon dioxide were calculated, averaged and analyzed with a paired sample $t$-test. 
Heart rate measured during the expired air collections were averaged and analyzed with a paired sample $t$-test. All data are reported as mean $\pm \mathrm{SD}$ and significance was set at alpha level of $p<0.05$.

\section{Results}

\subsection{Isometric Force of Knee Extensors}

The force during iMVC at baseline for both conditions were not different (downhill: $571 \pm 97$, level: $568 \pm 99 \mathrm{~N}, p>0.05)$. The maximal isometric force was not different immediately following level running (Post: $554 \pm 94 \mathrm{~N}, p>0.05$ ), but was reduced following downhill running (Post: $467 \pm 200 \mathrm{~N}$, $p<0.05)$. The decrease in force for the iMVC was $17.2 \pm 7.6 \%$ after downhill running.

\subsection{Level and Downhill Running Comparison}

The running speed was higher for downhill running (downhill: $13.5 \pm 3.2$, level: $9.6 \pm 2.2 \mathrm{~km} \cdot \mathrm{h}^{-1}$, $p<0.05)$. Downhill and level running bouts had $\mathrm{VO}_{2}\left(2.20 \pm 0.33 v s .2 .28 \pm 0.51 \mathrm{~L} \cdot \mathrm{min}^{-1}, p>0.05\right)$, $\dot{\mathrm{V} C O} 2\left(2.0 \pm 0.3\right.$ vs. $\left.2.0 \pm 0.5 \mathrm{~L} \cdot \mathrm{min}^{-1}, p>0.05\right)$, respiratory exchange ratio (RER) $(0.89 \pm 0.05 v s$. $0.89 \pm 0.03, p>0.05)$ and heart rates $\left(147 \pm 19 v s .143 \pm 16\right.$ beats $\left.\cdot \mathrm{min}^{-1}, p>0.05\right)$ that were not different indicating matched intensity and metabolic demands.

Figure 1a,b show the ventilatory equivalents for $\mathrm{O}_{2}$ and $\mathrm{CO}_{2}$ for downhill and level running, respectively. Ventilatory equivalents for $\mathrm{O}_{2}$ (downhill: $29.7 \pm 3.3$, level: $27.2 \pm 1.6, p<0.05$ ) and $\mathrm{CO}_{2}$ (downhill: $33.2 \pm 2.7$, level: $30.4 \pm 1.9, p<0.05$ ) were $7.1 \%$ and $8.3 \%$ higher for downhill running, respectively.

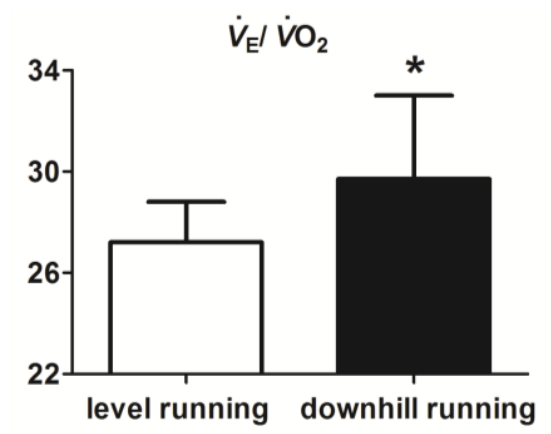

(a)

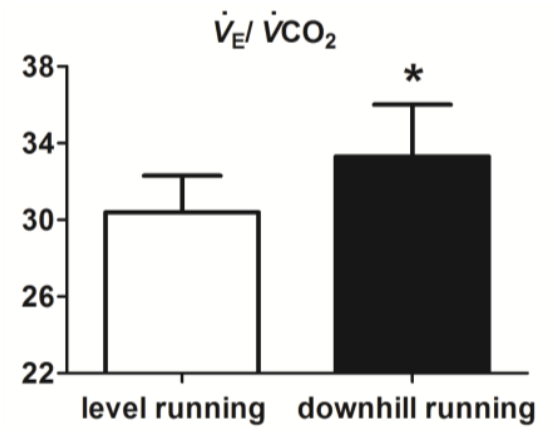

(b)

Figure 1. (a) Ventilatory equivalent for oxygen during intensity matched level and downhill running at $60 \%$ of maximal MET. Values are mean \pm SD. * indicates the ventilatory equivalent is significantly elevated in the downhill compared to the level running condition ( $p<0.05$ ); (b) Ventilatory equivalent for carbon dioxide during intensity matched level and downhill running at $60 \%$ of maximal MET. Values are mean \pm SD. * indicates the ventilatory equivalent is significantly elevated in the downhill compared to the level running condition $(p<0.05)$. 


\section{Discussion}

The major finding of the present study was that whole-body moderate intensity exercise (i.e., $60 \%$ of maximal MET) with primarily eccentric contractions of m.quadriceps femoris (i.e., downhill running) was performed with lower breathing efficiency than matched-intensity exercise with primarily concentric contractions (i.e., level running). Similarity in physiological $\left(\dot{\mathrm{V}}_{2}, \dot{\mathrm{V}} \mathrm{CO}_{2}\right.$, and heart rate) and metabolic responses (i.e., RER) confirmed that the level and downhill running bouts were performed with matched intensity and metabolic demands. The successful matching of exercise intensities resulted in a higher downhill running speed as the oxygen demand during downhill running is normally less than that for level running at the same speed [14]. Downhill running resulted in substantial isometric force deficits of the m.quadriceps femoris $(17 \pm 7.6 \%)$, which is comparable to other studies using downhill running [15-17]. For both running bouts, the ability of participants to produce maximal isometric force was measured immediately post-exercise suggesting that fatigue may have caused some of the force deficits. However, because the bout of level running did not affect the ability to produce maximal isometric force, this supports the suggestion that the force deficits following the downhill running bout were primarily the result of muscle damage.

Reduced breathing efficiency during moderate-intensity muscle-damaging downhill running exercise may be related to different mechanical and neural events compared to non-damaging level running. Interestingly, analysis of the ventilatory equivalents over time during the running bouts indicated a time effect for the ventilatory equivalent for $\mathrm{CO}_{2}$ for both level and downhill running (unpublished observations). In general, cardiovascular and ventilatory adaptations during exercise may result from responding to mechanical distortion or metabolic by-products from exercising skeletal muscle through thinly myelinated (group III) and unmyelinated (group IV) muscle afferents [18]. Because the exercise intensity was matched for level and downhill running bouts, greater mechanical distortion from the higher downhill running speed may have occurred, as eccentric contractions are also known to produce higher forces. Group III afferents are sensitive to mechanical distortion and have a large response to muscle stretch [19]. In addition, the ventilation rate during muscle activity is suggested to be related to activity of group III and IV afferents by distension of blood vessels [20]. This observation can be linked with potential disruption of the microcirculation during eccentric exercise induced muscle damage [21], and this could have resulted in an elevation of minute ventilation [22]. Finally, impairment of group III and IV muscle afferents by lumbar intrathecal fentanyl injections reduced the ventilatory equivalent for $\mathrm{CO}_{2}$ during steady state cycling [23], thus damage-inducing downhill running exercise may occur with elevated discharge of group III and IV afferents, in turn elevating the ventilatory equivalents for $\mathrm{O}_{2}$ and $\mathrm{CO}_{2}$. Therefore, it is possible in the present study that the type III and IV afferents had increased discharge during downhill running affecting the ventilatory response. This neurophysiological response is further supported by the observation that contraction type during fatiguing tasks can affect group III and IV afferent fibres after the activity, with eccentric contractions affecting afferent activity more than concentric contractions [24]. Additional support of increased afferent discharge may come from the perception of muscle discomfort experienced during the downhill running. All participants reported increased muscle discomfort during the downhill running, while no such reports were given during the level running. The muscle discomfort may provide a stimulus for the ventilatory response via mechanical 
stimulation of nociceptive muscle afferents $[25,26]$ with a large number of group IV afferents also being nociceptors [27].

It needs to be acknowledged that no measurements of breathing frequency and tidal volume were taken. It cannot be excluded that higher breathing frequency values during downhill running may have resulted in reduced tidal volume, increased dead space volume and inefficient alveolar ventilation. Such respiratory events could explain the higher ventilatory equivalents for downhill running.

\section{Conclusions}

This is the first study to examine the breathing efficiency during intensity-matched whole-body dynamic exercise with primarily eccentric and concentric contractions at moderate intensity (i.e., 60\% of maximal MET). Future work should examine the breathing efficiency at low and high exercise intensities of matched-intensity non muscle-damaging and muscle-damaging running protocols. It would also be of interest to examine the breathing efficiency of level and downhill running at similar speeds. In addition, it would be of interest to examine the discharge patterns of group III and IV afferents for matched-intensity whole-body dynamic exercise. It is concluded that breathing is less efficient during muscle damage-inducing downhill treadmill running at moderate intensity than intensity matched level treadmill running. These findings may have implications when using downhill treadmill exercise in clinical populations with respiratory diseases where breathing efficiency is already compromised.

\section{Author Contributions}

All authors were involved in study design, data collection, data interpretation, and manuscript writing. Willems and Cook were involved in data analysis.

\section{Conflicts of Interest}

The authors declare no conflict of interest.

\section{References}

1. Cooper, C.B.; Storer, T.W. Exercise and Testing and Interpretation: A Practical Guide; Cambridge University Press: Cambridge, UK, 2001.

2. Ofir, D.; Laveneziana, P.; Webb, K.A.; Lam, Y.M.; O’Donnell, D.E. Sex differences in the perceived intensity of breathlessness during exercise with advancing age. J. Appl. Physiol. 2007, 104, 1583-1593.

3. Rasmussen, B.; Klausen, K.; Clausen, J.P.; Trap-Jensen, J. Pulmonary ventilation, blood gases, and blood pH after training of the arms or the legs. J. Appl. Physiol. 1975, 38, 250-256.

4. Armstrong, N.; Davies, B. An ergometric analysis of age group swimmers. Br. J. Sports Med. 1981, 15, 20-26.

5. Laursen, P.B.; Rhodes, E.C.; Langill, R.H.; Taunton, J.E.; McKenzie, D.C. Exercise-induced arterial hypoxemia is not different during cycling and running in triathletes. Scand. J. Med. Sci. Sports 2005, 15, 113-117. 
6. Gavin, T.P.; Stager, J.M. The effect of exercise modality on exercise-induced hypoxemia. Respir. Physiol. 1999, 115, 317-323.

7. Minetti, A.E.; Moia, C.; Roi, G.S.; Susta, D.; Ferretti, G. Energy cost of walking and running at extreme uphill and downhill slopes. J. Appl. Physiol. 2002, 93, 1039-1046.

8. Bigland-Ritchie, B.; Woods, J.J. Integrated electromyogram and oxygen uptake during positive and negative work. J. Physiol. 1976, 260, 267-277.

9. Warren, G.L.; Lowe, D.A.; Armstrong, R.B. Measurement tools used in the study of eccentric contraction-induced injury. Sports Med. 1999, 27, 43-59.

10. Twist, C.; Eston, R.G. The effect of exercise-induced muscle damage on perceived exertion and cycling endurance performance. Eur. J. Appl. Physiol. 2009, 105, 559-567.

11. Davies, R.C.; Eston, R.G.; Poole, D.C.; Rowlands, A.V.; DiMenna, F.; Wilkerson, D.P.; Twist, C.; Jones, A.M. Effect of eccentric exercise-induced muscle damage on the dynamics of muscle oxygenation and pulmonary oxygen uptake. J. Appl. Physiol. 2008, 105, 1413-1421.

12. Gandevia, S.C. Spinal and supraspinal factors in human muscle fatigue. Physiol. Rev. 2001, 81, $1725-1789$.

13. Jones, A.M.; Doust, J.H. A 1\% treadmill grade most accurately reflects the energetic cost of outdoor running. J. Sport Sci. 1996, 14, 321-327.

14. Robergs, R.A.; Wagner, D.R.; Skemp, K.M. Oxygen consumption and energy expenditure of level versus downhill running. J. Sports Med. Phys. Fitness 1997, 37, 168-174.

15. Eston, R.G.; Lemmey, A.B.; McHugh, P.; Byrne, C.; Walsh, S.E. Effect of stride length on symptoms of exercise-induced muscle damage during a repeated bout of downhill running. Scand. J. Med. Sci. Sports 2000, 10, 199-204.

16. Chen, T.C.; Nosaka, K.; Tu, J.H. Changes in running economy following downhill running. J. Sports Sci. 2007, 25, 55-63.

17. Green, M.S.; Doyle, J.A.; Ingalls, C.P.; Benardot, D.; Rupp, J.C.; Corona, B.T. Adaptation of insulin-resistance indicators to a repeated bout of eccentric exercise in human skeletal muscle. Int. J. Sport Nutr. Exerc. Metab. 2010, 20, 181-190.

18. Kaufman, M.P.; Hayes, S.G.; Adreani, C.M.; Pickar, J.G. Discharge properties of group III and IV muscle afferents. Adv. Exp. Med. Biol. 2002, 508, 25-32.

19. Kaufman, M.P.; Longhurst, J.C.; Rybicki, K.J.; Wallach, J.H.; Mitchell, J.H. Effects of static muscular contraction on impulse activity of groups III and IV afferents in cats. J. Appl. Physiol. Respir. Environ. Exerc. Physiol. 1983, 55, 105-112.

20. Haouzi, P. Tracking pulmonary gas exchange by breathing control during exercise: Role of muscle blood flow muscle blood flow. J. Physiol. 2014, 592, 453-461.

21. Kano, Y.; Padilla, D.J.; Behnke, B.J.; Hageman, K.S.; Musch, T.I.; Poole, D.C. Effects of eccentric exercise on microcirculation and microvascular oxygen pressures in rat spinotrapezius muscle. J. Appl. Physiol. 2005, 99, 1516-1522.

22. Haouzi, P.; Chenuel, B.; Huszczuk, A. Sensing vascular distension in skeletal muscle by slow conducting afferent fibers: Neurophysiological basis and implication for respiratory control. J. Appl. Physiol. 2004, 96, 407-418. 
23. Amann, M.; Blain, G.M.; Proctor, L.T.; Sebranek, J.J.; Pegelow, D.F.; Dempsey, J.A. Group III and IV muscle afferents contribute to ventilatory and cardiovascular response to rhythmic exercise in humans. J. Appl. Physiol. 2010, 109, 966-976.

24. Martin, V.; Dousset, E.; Laurin, J.; Gondin, J.; Gautier, M.; Decherchi, P. Group III and IV muscle afferent discharge patterns after repeated lengthening and shortening actions. Muscle Nerve 2009, 40, 827-837.

25. Duranti, R.; Pantaleo, T.; Bellini, F.; Bongianni, F.; Scano, G. Respiratory responses induced by the activation of somatic nociceptive afferents in humans. J. Appl. Physiol. 1991, 71, 2440-2448.

26. Gleeson, M.; Blannin, A.K.; Walsh, N.P.; Field, C.N.; Pritchard, J.C. Effect of exercise-induced muscle damage on the blood lactate response to incremental exercise in humans. Eur. J. Appl. Physiol. Occup. Physiol. 1998, 77, 292-295.

27. Mense, S. Nociception from skeletal muscle in relation to clinical muscle pain. Pain 1993, 54, 241-289.

(C) 2015 by the authors; licensee MDPI, Basel, Switzerland. This article is an open access article distributed under the terms and conditions of the Creative Commons Attribution license (http://creativecommons.org/licenses/by/4.0/). 